\title{
CONTRIBUTION TO THE STUDY OF THE CORTICAL SENSORY AREAS.
}

\author{
BY G. L. WALTON, M.D., BOSTON, U.S.A.
}

Physician to the Neurological Department, Massachusetts General Hospital;

Clinical Instructor in Neurology, Harvard University;

AND

W. E. PAUL, M.D., BOSTON, U.S.A.

Assistant Physician to the Neurological Department, Massachusetts General Hospital.

IT is with confidence of doing no great violence to prevailing views that we present for further study a working plan, already outlined in our recently published article on "Astereognosis," 1 a plan falling in line with the views of Bastian, in that it accords a sensory function to both the Rolandic and the parietal regions, and recognises the gyrus fornicatus as a possible sensory seat.

It is true that the steady accumulation of evidence, experimental and clinical, establishing a sensory representation in the central convolutions, has somewhat overshadowed the claims of the parietal lobes to a share in this function; in fact, many authorities now regard the Rolandic region as the sole cortical seat of both muscular and cutaneous sensations. It is also true that little positive, and some negative, clinical evidence has been collected bearing upon the experiments of Ferrier, and of Horsley and Schäfer on the mesial surface of the brain. The supporters of the Rolandic region generally allow, however, that the sensory area exceeds the motor, particularly in the direction of the parietal gyri. Nor are authorities wanting who still

' Journal of Nervous and Mental Disease, April, 1901. 
favour the sensory function of the gyrus fornicatus. and hippocampus.

Bastian, ${ }^{1}$ in 1887, while placing the kinæsthetic centre in the central convolutions (a view now very widely accepted), still favoured the views of Ferrier regarding cutaneous sensations, a segregation of function, endorsed by Horsley and by Schäfer, to which our theory practically subscribes. We would suggest, however, an anatomical and physiological relationship between those cortical areas somewhat at variance with Bastian's views as we understand them. This author, while not definitely designating the course of the fibres transmitting the impressions from muscle, fascia, tendon and skin, received by the kinæsthetic centre, conveyed the idea that all these impressions proceed directly to the Rolandic and marginal areas. He called attention to the fact, however, that extrinsic sensorial stimuli-for example, touch and smell-also play a part, adding that large tracts of the brain ought to be concerned with the registration of kinæsthetic impressions for future use in the guidance of all voluntary movements. The motor mechanism thus stimulated he placed below the cortex. In his later publication ${ }^{2}$ (1893) he divides sensation into two varieties and gives them separate seats; the one, resulting from the execution of movements and serving to reproduce, guide and regulate the new execution of such movements, he places in the Rolandic and the marginal areas, while he places the registry of touch and general sensibility in the limbic lobe. The latter variety of sensation incites to movement, but is in no sense kinæsthetic. The former seat of sensation includes such tactile elements as have to do with kinæsthetic memories; for example, from the deeper structures.

In the plan we favour the central convolutions are not made an independent centre, but a centre assembling the various sensory memories from other parts of the cortex (for the upper extremity from the parietal lobe and for the

- Brain, April, 1887.

2 "Hysterical or Functional Paralysis," Appendix C. J. B. Lippencott Co., 1893. 
lower extremity from the gyrus fornicatus), itself receiving directly, at the most, only the fibres conveying muscle-sense in its narrowest meaning. Nor does our plan reject, as does that of Bastian, the motor function of the cortex.

A fundamental difference, again, between our plan and that of Verger ${ }^{1}$ consists in according to the cortical centres in the parietal lobes and perhaps in the gyrus fornicatus, the less differentiated sensations of pain, of temperature and of contact which he places at a lower level.

Our proposition is based on the fact that we need not linit the number of successive cortical neurones taking part in the reception and the transmission of sensory stimuli. Analogy with tracts already accepted would point to the probability that several, possibly many, neurones must be interposed between the simple reception of a sensation and the assemblage of the associated memories representing the high grade of sensation which furnishes the stimulus for so-called voluntary motion.

We need only allude to this connection to the recurrence of sensory neurones in the spinal cord, medulla, and thalamic regions, a recurrence which we have no anatomical reason to believe suddenly ceases in the hemispheres, which represent merely a higher development of homologous structures. The widespread location of sensory cells in the cord, occupying, as they do, a large portion of the posterior gray matter, should also prepare us to consider favourably a scheme which involves the diffusion of cerebral sensory neurones over a large area.

Again, a succession of neurones is acknowledged to exist in the cortical sphere of special sensation, as evidenced by the generally accepted theory of speech mechanism, which includes, starting, e.g., from the visual side (a.) a cortical visual area in the occipital region; (b) a higher area in the angular gyrus concerned in mind vision ; $(c)$ an aggregation in Broca's convolution of the muscular and other memories concerned, known as the kinæsthetic speech centre; and (d) the so-called motor centres in the lower

'Archives Generale de Medicine, November, December, 1901. 
central region, for the laryngeal, pharyngeal, lingual and lower facial muscles taking part in articulation. Our theory supposes similarly $(a)$ reception of simple sensations (pain, temperature, contact); (b) realisation of the meaning of these sensations; (c) an aggregation of the cutaneous and muscular memories concerned in the stereognostic sense ${ }^{1}$ or "active touch" (including spacing, localising and position senses); and $(d)$ the corresponding motor mechanism.

This comparison may be represented by the accompanying diagrams.

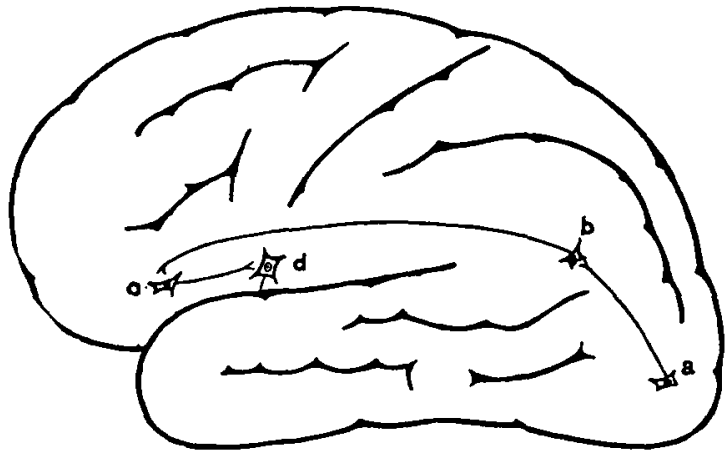

Fig. 1.

Orders of cortical neurones required for one of the paths concerned in the visual side of the speech mechanism.

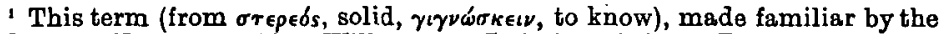
studies of Hoffman, Abba, Williamson, Dejerine, Sailer, Zenner, Dercum, Mills, Burr, and others, seems preferable in view of the fact that while the complete recognition of objects by the hand requires movement of the fingers, a certain degree of this sense may exist without such movement. For example, the loss of this sense can be approximstely tested in the sole of the foot, without the aid even of the posture sense, by determining whether the patient can distinguish between a silver piece and a pencil applied transversely, the test being supplemented by that for the spacing and localising senses, important elements in the recognition of objects.

It has been suggested by Burr that in expressing the negative of this sense stereoagnosis is more accurate than astereognosis, but this suggestion, while well founded from a philological point of view would give rise, we fear, to much confusion on account of the similarity in appearance of the word stereognosis and stereoagnosis. The expression "stereognostic sense" has been also criticised and replaced by the expression "stereognostic faculty" ; but this criticism seems to us unfounded, inssmuch as one of the legitimate definitions of the word "sense" includes recognition by the intellect. We speak, for example, of the sense of justice, the sense of fitness, and Webster quotes Tennyson's use of the term "sense of the lover" with a similar significance. 


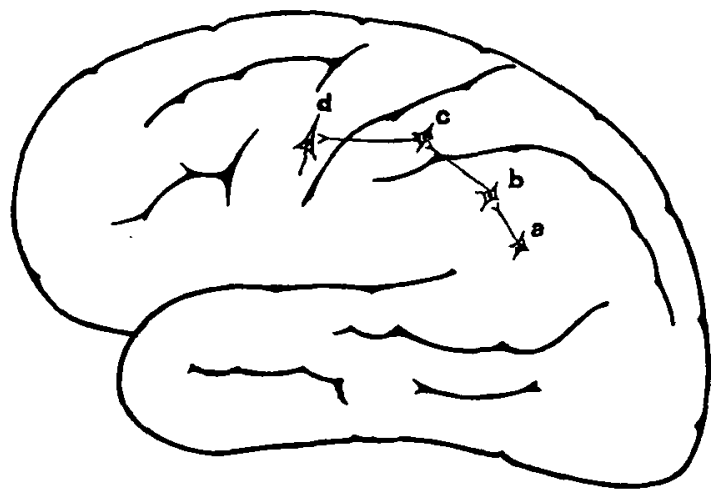

FIG. 2.

Corresponding orders of neurones, suggested as forming part of the hand movement mechanism from the point of view of one of the simple sensations contributing to the stereognostic sense.

While we do not attempt the exact localisation of the separate factors entering into this complex process, and while it seems doubtful if either clinician or physiologist will be ever in position to do so, it does seem that we are justified in placing the lower of the neurones posteriorly to the gyri in which the corresponding motor areas are found, while the highest centre must be placed in the central convolutions, closely approximating, if not overlapping, the corresponding nuotor region. In other words, we should favour, for the upper extremity, the middle portion of the central convolutions as the seat for "active touch," or the stereognostic sense, and the parietal lobes for the lower grade of sensory memories (contact, pain and temperature). For the lower extremity the stereognostic sense should be placed in close association with the motor leg centre. We approach the question of the lower sensory neurones for this extremity with less confidence, but it seems not improbable that the gyrus fornicatus, lying adjacent to the motor centres for this part of the body, may furnish the principal seat, though for reasons to which we shall allude later, far less satisfaction is found in the clinical study of this region than in the study of the convexity of the brain.

Regarding the location of "muscle sense" or "muscle memories," there is wide diversity of opinion. While the 
weight of authority favours the Rolandic region for this function, Dana, ${ }^{1}$ for example, who favours the central gyri for all other sensory functions, places the muscular memories in the parietal lobe, a situation hard to reconcile with his idea of the unity of the cortical sensory motor memory organ. The divergence of opinion is possibly in part due to the vague interpretation of the expression "muscle sense." Fränkel wisely adopts an expression which implies merely recognition of the position of the parts without reference to the question whether this recognition involves muscle articular, or cutaneous, stimuli, or all three. We use the term "posture sense" for this reason. The muscular memories concerned in this sense we are inclined to place in the central convolutions, giaided perhaps partly by our personal observations, and partly because it seems established that the fibres from the fillet pass to this region, whether directly (Fleschig and Hoesel), or with interruption at the thalamus (Mahaim, von Monakow). It seems not improbable, however, that the cutaneous and articular fibres concerned in posture sense pass first to the parietal, while the fibres from the muscle spindles pass to the central convolutions to take part in "active touch" without intervention of further neurones, though such hypotheses are perhaps too conjectural to detain us at a time when such comparatively simple functions as those of contact, pain and temperature are still under discussion.

The very frequent escape of the pain and temperature senses, compared with that of contact, in lesions of the central convolutions, renders it probable that these two senses have a separate representation in the cortex, just as their fibres run a separate course in the spinal cord. This centre may be further removed from the central region than that for touch, for in recorded cases of apparently limited Rolandic lesion the statement frequently appears that tactile as well as stereognostic sense is impaired. This does not necessarily establish the central seat of contact sense, for it is evident that many observers have used the term "tactile sense " loosely, referring only to the loss of "active touch"

' Journal of Nervous and Mental Disease, December, 1894. 
and even when it appears that contact sense is really impaired in these cases, the impairment is evidently slight, for the patients are described as calling two points one, as localising badly, and as being unable to distinguish between different objects, descriptions in themselves implying a certain degree, at least, of contact sense.

We desire particularly to disclaim the suggestion that the cortical sensory tract is limited to the course we have sketched. We attempt no suggestion as to the distance apart of the cells concerned, or of the length and course of the connecting fibres, whether direct or tortuous. It is not irnpossible, for example, that some of the cells lie much more superficially than others, or even that the cells of some. neurones directly overlie those of the succeeding neurones.

The diagram presented by Mr. Victor Horsley at the Congress of American Physicians and Surgeons, in 1888 (reproduced in Dana's article), represents three cells, one overlying the other, in the Rolandic region; lowest of all a great pyramidal cell for motion, above it a smaller cell of similar shape for muscular sense, and above this a still smaller cell of different shape for "slight tactile" sense. The supposition of Horsley that the small cortical cells are probably part of the sensory mechanism seems reasonable, and it may well be that the "active touch" area overlaps, or even extends more anteriorly than the corresponding motor centre. That all the sensory factors (including temperature, pain and contact) are so superimposed, however, seems to us most improbable.

We use the word "centre" in its broadest sense, meaning the physiological, not necessarily anatomical, groups of cells and fibres concerned in the process under discussion. In the case of the kinæsthetic area this group must be extensive, for it involves not only the muscle memories but also an aggregation of associative memories connected with the temperature, size, shape and weight of objects, their appearance, their sounds, the appearance and sound of their names in short it must be in connection with, and receive stimuli from every centre of sensory menories adding to our knowledge of the external world. Each of 
these factors plays a part in the complete aggregation of association memories preceding and stimulating a so-called voluntary movement however simple, for example, the closing of a window, though such movement may not necessitate the presence of all sources of the information. ${ }^{1}$

The recent valuable work of Cajal ${ }^{2}$ on the brain cortex may throw light on the anatomical substratum for the kinæsthetic centres. He describes a fundamental difference in the structure of the pre-Rolandic and the post-Rolandic convolutions. The anterior of these convolutions differs, he finds, from the rest of the cortex in the following respects : (a) Lack of plainly differentiated granular layer ; (b) great thickness of the layer of middle great and great pyramidal cells; and $(c)$ the presence of a specific nerve plexus consisting of strong exogenous nerve fibres lying in the network of the middle great layer.

The posterior central gyrus, on the other hand, resembles, he finds, the associative cortex, in containing (a) a well-defined granular layer; (b) a very slight layer of middle great and great pyramidal cells; and (c) a specific nerve plexus having another seat than that occupied in the anterior central convolution. Cajal infers that either the posterior convolution has a peculiar motor function requiring a different structure from the anterior convolution, or that its motor character is questionable, and that it represents rather an ideo-motor association centre whose stimu-

The demonstration of such a kinæsthetic centre would fall in line with the inferences of Henry Smith Williams in his "Story of 19th Century Science." Harper \& Brothers, 1900, p. 422.

". . . . most of the supposed isolated 'faculties' of higher intellection appear, upon closer analysis, as complex aggregations of primary sensations. and hence necessarily dependant upon numerous and scattered centres. Some 'faculties,' as memory and volition, may be said in a sense to be primordial endowments of every nerve cell, even of every body cell. . . . But such refinements of analysis, after all. cannot hide the fact that certain forms of bigher intellection involve a pretty definite collocation and elaboration of special sensations. Such specialisation, indeed, seems a necessary accompaniment of mental evolution. That every such specialised function has its localised centres of coordination, of some such significance as the demonstrated centres of articulate speech, can bardly be in doubt, though this. be it understood, is an induction, not as yet a demonstration. In other words. there is every reason to believe that numerous 'centres' in this restricted sense, exist in the brain that bave as yet eluded the investigator."

${ }_{2}$ Studien iiber die Hirnrinde des Menschen, 2 Heft ; Die Beucgungsrinde, von S. Ramón y Cajal. Uebersetzt, von Dr. J. Bresler (Leipzig, 1900). 
lation brings about movements in certain muscle groups. 'This author suggests that perhaps the small pyramidal and the polymorphous cells constitute the substratum for touch, pain and temperature senses, adding that although it is impossible to establish the true part taken by the different kinds of pyramidal cells, yet the possible hypothesis suggests itself that the pyramidal tract springs from the giant pyramidal cells and from some of the middle great pyramidal cells, while the "Balken-bahn" takes its principal, if not its sole origin in the small pyramidal cells, and perhaps also in the polymorphous cells.

The clinical and pathological arguments in favour of the plan suggested are :-

(1) Numerous cases have been reported with loss of the stereognostic sense, or "active touch," including loss of spacing, localising and position senses, but with preservation of pain, temperature and contact senses. This points to a centre for the aggregation of memories concerned in judgment of the nature of objects separate from the centres whose function is limited to the simple reception of the various sensory stimuli contributing to this aggregation.

(2) The fact has been established beyond controversy that "active touch," or the "stereognostic" sense, has a representation in the central gyri (Dana, Verger, and many others). Case after case has been carefully observed and reported in which Rolandic lesion has produced disturbance of spacing sense, of localising sense, of posture sense, and of the ability to recognise objects in the hand with closed eyes, as well as fumbling movements and ataxia.

(3) The temperature, pain and contact senses have been so often spared in lesions of the central gyri as to render it extremely improbable that this region is the seat of these sensations.

(4) When the parietal as well as the Rolandic region is found involved we often find, in addition to loss of active touch, loss of the temperature, pain, and tactile senses.

(5) The sensation of the lower extremity is often unimpaired in lesion of the convexity. 
The additional arguments needed to establish the theory are :-

(6) Cases of limited parietal lesion in which pain, touch, and temperature senses are lost.

(Even if astereognosis should also be found in lesions thus limited, the fact would not militate against our theory, for it is obvious that disturbance of the second grade of neurone would impair the sensory pictures and thus interfere with the stereognostic sense, just as lesions of the mind vision centre interfere with speech.)

(7) Cases of limited gyrus fornicatus lesion with sensory loss in the lower extremity.

The arguments against compound sensory areas are :-

(1) Cortical anæsthesia unaccompanied by motor paralysis is of rare occurrence. (A few cases presenting such isolated anæstbesia, are, however, on record, for example, by Mills, ${ }^{1}$ by Pierret, ${ }^{2}$ in whose care anæsthesia persisted after motor recovery, and by ourselves. ${ }^{3}$ )

(2) The reaction time of sensation of touch is brief, midway between that of smell and that of sight (Wundt). (But the reaction time required for the recognition of objects, which would represent the complete sensory process involving all the organs of neurones we have suggested, would certainly be much larger than that quoted, that is, than thirteen thousandths of a second.)

With reference to arguments 6 and 7 it is most important that cases showing such limitation should be put on record when found, together with the clinical report of all forms of sensation whether such report is positive or negative. Cases of tumour limited to these areas and accompanied by careful clinical records, are far less frequently found in the literature than those affecting the central gyri. Too few cases are recorded bearing definitely upon argument 5. Deeply seated lesions, as tumour or softening in the parietal lobe, must be eliminated on account of their liability to involve either the mesial surface

' Journal of Nervous and Mental Disease, May, 1900; University Medical Magazine, October, 1897.

Lyon Medical, 31 Janvier, 1886.

${ }^{3}$ Loc. cit. 
of the brain or the afferent fibres connecting this region with the thalamus. We should mention, however, an unusual case (hitherto unpublished), seen at the Massachusetts General Hospital in the clinic of Dr. W. L. Richardson. In this case an extensive meningeal hæmorrhage, confirmed by autopsy (Dr. Wright), compressed particularly the anterior parietal and post-central regions, the brain being found otherwise normal. This hæmorrhage caused in the arm moderate loss of contact sense and moderate astereognosis with diminution of spacing sense, but gave rise to no anæsthesia of the lower extremity. Posture, pain and temperature senses were intact in the arm; no loss of motion appeared in the arm or leg. The moderate impairment of function resulting from the pressure precludes citing the case as absolutely demonstrative of the suggestion that lesions of the convexity may spare the sensation of the lower extremity, but it is somewhat suggestive in this connection. The case is certainly worthy of record as exhibiting sensory loss, resulting from cortical lesion, without accompanying motor impairment.

With regard to the function of the gyrus fornicatus we are greatly handicapped in our clinical and pathological study in various ways.

In the first place the operative cases which furnish so large a part of the Rolandic material are practically wanting, for operation would rarely be advised on a tumour diagnosticated as invading the mesial surface of the brain. It is true that many of the tumours and softenings implicating the central convolutions must of necessity impair the function of the gyrus fornicatus or its fibres either by pressure or by direct extension; from such cases, however, few direct inferences can be drawn as regards the function of the gyrus fornicatus, though the inference is patent that we should be chary of deeming such cases negative in their bearing on this region. The only other cases from which even approximately accurate conclusions can be drawn are those coming to the autopsy table. Here, again, we find dearth of material in this connection, perhaps largely on 
account of the lack of that special interest on the part of the clinician which leads him in case of Rolandic lesion to first make careful and complete clinical records, then follow the case to post mortem, and finally to put it on record in the literature. Again, the sensation of the lower extremity is less often carefully studied than that of the upper, a fact still further narrowing the group of cases furnishing light on this branch of the subject.

In illustration of this lack of material we need only contrast the twenty limbic lobe cases collected by Dana ${ }^{1}$ in 1888, with the 142 Rolandic cases collected by the same author at the same date. Of even these twenty cases thirteen offer little aid as regards the gyrus fornicatus because the lesion only involved the gyrus hippocampus, fusiform lobe, or unsinate gyrus.

In four others of the twenty cases the lesion was described respectively as limited to the anterior half, the anterior third, the posterior part, "very limited" and "without any general anæsthesia," the last case being reported from a verbal communication, too vague, therefore, to be accorded serious consideration in a critical analysis.

In the remaining three cases involving the gyrus fornicatus it appears that numbness was present in some degree at least, for in one case numbness is reported in the foot, in another the statement is made that no marked anæsthesia was present, while in the third case the numbness was attributed to the fact that the lesion included also the central region.

The innumerable cases of Rolandic lesion on record as free from disturbance of sensation receive scant consideration at the hands of this author, and justly so, on account of (a) incomplete observation; (b) late observation after compensation has occurred; $(c)$ small lesion; and $(d)$ slowly developing lesion. If the same reasoning is applied to these twenty cases involving the mesial surface of the hemisphere, we are left with little or no pathological evidence worthy of serious acceptance, which negatives the gyrus fornicatus as a sensory area. It is also true, on the

I Journal of Nervous and Mental Disease, October, 1888.

VUL. XXIV. 
other hand, that we have as yet little satisfactory clinical evidence corroborating the experimental evidence in favour of this region.

Before reviewing the more extensive, and, it seems to us, satisfactory evidence in support of the first four arguments advanced, we may be pardoned for a digression, bearing upon the difficulty of collecting the clinical material for these studies.

Research based upon recorded cases is baffling at the best, on account of $(a)$ the vague localisation of lesion as recorded by the pathologist (for example, "under the parietal boss"); (b) on account of the uncertainty whether the ancesthesia results from the lesion described, or from pressure, œdema, or from other influence referable to remoter regions; and $(c)$ incomplete and inaccurate clinical records.

The second and third are the most frequent and troublesome of these drawbacks. Comparatively few of the many recorded conform even approximately to the requirements of Hale-White ${ }^{1}$-limited lesion, definitely localised, careful autopsical record, careful clinical study. The post-operative cases are peculiarly misleading. In illustration of the extent of post-operative symptoms as compared to those resulting from the original lesion may be cited the case of Albertoni and Brigatti (Revista Sperimentale de Fren., xix., January 1, 1893, abstract by Dana in Journal of Nervous and Mental Disease, December, 1894). In this case the tumour, the size of a hen's egg, was removed from the right central convolutions. Tactile, general, thermal, painful and muscular sense impressions, previously intact, were, after operation, affected over the whole left half of the body except the face.

In the case reported by Williams (New York Medical Journal, January 9, 1882, also abstracted by Dana), a compound fracture of the skull in the arm centre accompanied by laceration of the surface of the brain and slight loss of substance is said to have produced before operation,

'British Medical Journal, July 29, 1893. 
no disorder of sensation, though the arm below the elbow was completely paralysed. After recovery from operation, paræsthesia appeared in the left arm and leg and later examination showed persistence of anæsthesia of the fingers. Even here the character of the anæsthesia tends to support our contention, for the thermal and pain senses were intact, though articles were picked up with difficulty and in a fumbling manner, and the patient could not distinguish between a knife and a pencil held in the hand with the eyes closed.

Again, in the second of our personal cases, the removal of a bit of diseased cortex in the hand area was followed by an aphasia which limited the vocabulary to the words "yes" and "middling," with marked word deafness and mind blindness, the patient understanding only the simplest orders and being unable to imitate even the simplest motions. The sensory symptoms which accompanied the motor paralysis in this case prior to operation consisted in loss of recognition of objects in the hand with the eyes closed, impairment of posture sense, localising sense, spacing sense, and pressure sense, but no impairment of contact, pain, or temperature senses. The only indication of aphasia before operation was a moderate difficulty in finding words, no mind blindness nor word deafness. The post-operative sensory aphasia precluded detailed examination of sensation after the operation, but it is obvious that whatever results might have been obtained by such examination could hardly have been attributed to the original limited lesion in the central convolutions.

Finally, in a case mentioned by Verger (reported to him by Rocher), no sensory loss was caused by an abscess in the Rolandic region causing hemiparesis, but after its evacuation, active touch, position sense, and localisation of pain were lost. Even here the preservation of temperature, contact and pain senses brings this case in line with those we shall adduce to substantiate the theory of separate representation of the latter senses.

With regard to the incomplete and inaccurate records, a large proportion of reported cases must be discarded 
in the critical analysis on account of the meagre description of the sensory loss. Description limited to the words " anæsthesia of arm," "numbness of arm and leg," while useful, perhaps, in showing that cortical disease leads to sensory as well as motor irnpairment, are of little aid in determining the exact location of the different qualities of sensation. Even among the more carefully recorded cases there appears a tendency to use the word "tactile" in the vague manner to which we have alluded. For instance, Dana states of a certain case that the tactile sense is impaired in a case of Rolandic lesion with marked astereognosis, though in recording the defective spacing sense he states that two points widely separated were felt as one. It is obvious, therefore, that in this case "contact" sense was preserved, to a certain degree at least, and we are left in doubt whether it was definitely tested, or whether the loss of so-called tactile sense was limited to the defective judgment regarding the contact, in other words, to the sense of " active touch."

Before leaving this branch of the subject we must also remember that these investigations are pursued upon a class of patients often unable (whether naturally or from the cerebral disease) to understand the questions put to them, and to analyse their own sensations. In illustration of this difficulty we need only cite a case recently examined, but not published, by ourselves. This was a case of an uneducated woman about 60 years of age. She could neither read nor write, but possessed the average intelligence of her class. Right hemiplegia existed of six years' standing, with practical recovery of the right leg, but marked athetoid movements of the right arm. There was no paralysis of the face, and the patient found no difficulty in ordinary conversation. Posture sense even as high as the wrist was absolutely lost. Objects placed in the right hand (a purse, a knife, a pencil) were unrecognised with the eyes closed, whereas in the left hand they were promptly named. The temperature sense was unimpaired in the right, as in the left hand, the patient promptly distinguishing between the test-tubes of cold and of hot water and 
named them correctly. On analysis of the pain and tactile senses her answers were most misleading, apparently through lack of appreciation of the meaning of our questions. For example, when touched with a pointed object in the palm of the hand (with the eyes closed) and asked if she felt it, she invariably answered " no," and yet when she was touched with two points and asked to state whether she was touched with one or two, she always answered promptly "one point," adding, "it hurts," "it's sharp," meantime drawing her hand away quickly. When touched with the same sharp point in the same manner, and asked if it hurt, she invariably answered "no." It seemed apparent therefore, that both pain and contact senses were present, notwithstanding her answers. This case is mentioned in this connection merely to show the difficulty of examining persons with defective intelligence, but not as absolutely demonstrating the persistence of contact and pain senses. For the latter purposes this case would be of no material assistance as we have no means of demonstrating the limits of the lesion.

Such considerations as above outlined must be borne in mind in every attempt to analyse recorded cases of defective sensation in cerebral lesion, and must lead to the elimination of very many of the tabulated cases.

It is hardly necessary to quote individual cases from the large number which corroborate the first of the arguments advanced in defence of our position, that is, the constancy of astereognosis in Rolandic lesions. Among the twentyfive personal and other cases contained in Dana's most recent collection (1894), wherever mention appears of active touch or its components, in connection with limited Rolandic lesion, this sense is found defective. The same is true of the collected cases of Verger. Four such cases coming under our own observation were published in our previous paper. In opposition to this view Mills ${ }^{1}$ states that innumerable cases of Rolandic lesion have been recorded without loss of sensation. Our own study of such records would indicate that the stereognostic sense

' “ The Nervous System and its Diseases," Lippencott, 1898, p. 341. 
had not been as a rule investigated. Such cases do tend, however, to substantiate the claim that the touch, temperature and pain senses bave a different seat, for some or all of these are the senses ordinarily tested, and in fact they are sometimes mentioned in the negative cases alluded to, for example, in one of the cases reported by Hoppe. ${ }^{1}$

With regard to the frequency with which temperature and pain senses remain intact in lesions limited to the Rolandic area, we find, taking from the same collections those whose definiteness of location and careful clinical records justified their use (Knapp, Williams, Dana, Steele, Thomas, Starr, Mason, Bremer and Carson, Darkschewitsch, Albertoni and Brigatti, Frank and Church, Laycock, Verger, Verger and Bougard, Rocher, Raymond, Wernicke) that the temperature sense was normal in about half the cases in which this sense was recorded, and the pain sense in more than half of the corresponding cases. The "touch" sense was normal in several instances, although astereognosis was present. The number of cases analysed was too small for statistical purposes, to say nothing of the fact that in these selected cases we have included the Rolandic case of Darkschewitsch, assuming that he included pain, touch and temperature in the statement that all forms of sensation were lost. Again, either view might be taken of the case of Albertoni and Brigatti, in which a large tumour in the Rolandic region is recorded as producing no loss of these senses before operation, but of their affection after it, obviously the result of the operation rather than of the tumour.

The results of this analysis is given therefore, merely as suggestive and for comparison with the cases known to be extensive, but without claim of statistical accuracy. This variety of research is discouraging on account of the laxity in sensory records and the indefinite knowledge of the lesions. The latter must of necessity always offer a serious obstacle, but it is to be hoped that the former will disappear as interest in this subject becomes more general.

Our personal cases, in which the physical examinations

' Joumal American Medical Association, February 2, 1901. 
were made with special reference to the questions under discussion (published in detail in our previous article), would certainly indicate that preservation of touch, pain and temperature senses with absence of the stereognostic sense is common in Rolandic lesion, and before the view of Mills is accepted (namely, that the stereognostic sense has its seat in the parietal region) the burden of proof should be sustained by at least matching such cases by cases in which the stereognosis was the only sensory symptom resulting from parietal lesion.

Case 1.-Young woman. Numbness of left arm, six weeks' duration. Examination of sensation of upper extremity showed astereognosis with loss of position, spacing and pressure, slight impairment of touch, and preservation of temperature and pain senses. Five days later hemiplegia appeared. Operation on arm area in the Rolandic region. Evacuation of cyst. Death after one month. Autopsy refused.

Case 2.-Young woman. Numbness of right hand one month ago, followed in a few days by loss of power. Several days later loss of power and sensation in right leg. Upper extremity showed impairment of stereognostic sense and lessening of pressure, position, spacing and localising senses. Preservation of contact, temperature and pain senses. Headache, vomiting, optic neuritis. Knee-jerks increased on both sides. Babinski reflex on the right.

Operation.-Discoloured area size of half-dollar in Rolandic region. Removal of small fragment only. Operation followed by marked aphasia, large cerebral hernia, relief of pressure symptoms, but no amelioration of sensory or motor symptoms.

Case 3.-Young woman. Convulsions two years ago followed by paralysis of left leg. Gradual increase of paralysis with spastic symptoms. Repeated Jacksonian convulsions, spasm always beginning in great toe and followed by temporary weakness in left arm. Face unaffected. Optic neuritis. Both kneejerks increased. Ankle clonus and Babinski reflex on left. No loss of sensation in hand. In foot loss of spacing and posture: senses. Patient could not distinguish between silver piece and pencil applied transversely to sole of foot. Pain, temperature andl. contact senses normal.

Operation.-Just behind upper end of fissure of Rolando. Brain tissue discoloured, bulging, vascular. Hæmorrhagic focus. 
from which old clot, size of thumb, removed. Diagnosis from bit of cortex removed, red softening. After operation same loss of sensation with added slight blunting of pain and contact, not of temperature sense.

Case 4.-Woman, aged 92. Twelve days before examination developed choreiform movements in the left arm, gradually spreading to face and leg of same side. Strength not notably impaired. Grasp good on both sides. All voluntary movements made, but in an incoordinate manner. Loss of stereognostic sense in left hand and foot with loss of spacing, position and localisation senses, but there was preservation of contact, pain and temperature senses. Death six days later. No autopsy. (This case illustrates the dissociation of pain, temperature and contact senses from those of spacing, localising and "active touch," and while the seat of lesion was not verified by autopsy, there can be little doubt that it was superficial and in or near the Rolandic region.)

In all four of these cases astereognosis was present, therefore, with preservation (before operation) of temperature and pain senses, and in three of the four contact sense (tested with special care), was found normal, and in the fourth was only moderately impaired. The fact that in one of the cases after operation slight blunting of pain and contact senses appeared does not impair our conclusions in view of the common post-operative extension of symptoms.

This result certainly suggests that the representation of the temperature and pain senses and probably of the tactile (aside from active touch) lies mainly outside of the Rolandic area. Indeed, when we bear in mind the prevailing laxity in the use of the word "tactile," and the possibility, even probability, that in some, at least, of these cases the limited lesion mentioned was not responsible for all the symptoms, we feel that these cases give rise to a strong presumption in favour of a separate seat for the sensations at least of pain and temperature, and probably also for that of contact. This presumption is fortified by the study of cases in which the lesion described was more extensive, including, for example, the parietal lobes, the angular gyrus and the occipital region, and extensive implication of the centrum ovale. 
Of such cases we find in the same collection four. In all these cases there was loss of touch and pain sense, and in three of the four, loss of temperature sense. In the fifth this sense was not mentioned. As regards these senses, the cases of extensive lesion offer, then, marked contrast to the cases of limited Rolandic lesion. The cases are those of Madden ${ }^{1}$ (post-central, superior parietal, suprasylvian, anterior portion of angular gyrus and occipital convolutions. Loss of pain and touch, temperature not mentioned); of Wilson, ${ }^{2}$ (tumour of central region with softening of tissue around the tumour and white softening of whole centrum ovale, loss of pain, touch and temperature), of Dejerine and of Long. The following were the essential features of the two last mentioned cases :-

Case of Dejerine (Rev. neurologique, Mars 15, 1893, p. 51).

The lesion consisted of softening in the inferior parietal, the central, the first and second frontal, and first temporal gyri. There was (left) hemiplegia of the face, arm and leg, the arm being more affected than the leg. In the arm there was complete loss of contact, pain and temperature senses. In the lower extremity the same senses were less plainly felt than on the other side, but were "far from being abolished." Muscle sense lost in arm, very slightly in the leg.

Case of Long (These de Long, observation 54, p. 268).

The lesion was a plaque occupying the foot of the second frontal, the lower part of the Rolandic convolutions, all of the inferior parietal, and the angular gyrus; the anterior part of the occipital and the upper and posterior part of the second temporal and part of the first temporal lobes were also involved. There was notable diminution of the tactile, pain and temperature senses in the hand; the muscle sense was extremely altered.

The case of Hudson ${ }^{3}$ apparently falls between the limited and the extensive classes, in that the traumatic meningeal hæmorrhage $\frac{3}{4}$ inch thick, reinoved from the central region, extended, according to the diagram, beyond the limits of

'Journal of Nervous and Mental Disease, February, 1893, p. 125.

2 Lancet, February 27, 1892, p. 482.

* "Annals of Surgery," 1893, p. 421. 
the central gyri. In this case astereognosis was marked, temperature and pain senses were impaired but not lost. Touch sense aside from active touch was not noted.

The following (hitherto unpublished) personal observation though unverified by operation or autopsy, is of great interest in this connection.

Case 5.-Man, aged 72, with marked atheroma. Intermittent twitching of the right side of the face first appeared five weeks before examination. Each attack lasted a few minutes, and the frequency had increased to about seven a day. Three weeks before examination a similar spasm of the right hand appeared. These attacks were followed by motor paresis of face and hand. No headache, no nausea nor vomiting, no optic neuritis.

Sensory examination showed complete loss in the hand of all senses, including contact, pain and temperature, the anæsthesia being bounded sharply on the palmar surface by a transverse line just above the wrist, on the dorsal surface by a similar line just above the knuckles.

In the lower extremity there was no loss of temperature, contact, or pain sense, but there was marked loss of spacing sense in the sole of the foot, and the patient was unable to tell the difference between the point and side of a pencil. Tactile hyperæsthesia accompanied the astereognosis. The gait was normal and all movements of the foot were made, the knee-jerk was active but not markedly exaggerated; there was no Babinski reflex. The grasp was normal, but the movements of the right hand were awkward. The patient was able to make the necessary movements for touching the thumb and little finger, but was unable to guide them even with the eyes open. Typical right facial paralysis was present with drooling, difficulty in exhibiting teeth, thickness of speech and deviation of the tongue to the right. It was hard to choose and use words, but there was no sensory aphasia.

The difference both in type and degree of the anæsthesia in the upper and lower extremity was striking in this case. The limits of the lesion, probably softening, are, of course, uncertain. but the suggestion forcibly presents itself that the escape of numbness, other than astereognosis in the foot, was due to the integtity of the mesial surface of the brain, and that the complete loss of pain, temperature, and contact senses in the hand, pointed to involvement of the parietal, as well as the Rolandic, convolutions. 
In conclusion, though we have not yet established our theory, it seems to us that we have offered presumptive evidence of sufficient weight to justify taking it into consideration in the further study of this subject. Especially desirable are cases of limited parietal or gyrus fornicatus lesion accompanied by careful clinical records.

We would particularly emphasise the importance of recording the sensations of both extremities in every case of supposed cerebral lesion. In making such records it is important to include (1) the temperature sense; (2) the pain sense ; (3) contact sense, that is, the ability of the patient to recognise the fact that he is touched; (4) the localising sense, including localisation of pain; (5) posture sense, including both, noting $(a)$ whether the patient knows that the part is moved, and $(b)$ whether be knows the direction in which it is moved; (6) spacing sense ; (7) pressure sense ; (8) stereognostic sense, or ability to recognise objects in the hand with eyes shut. (This sense may be approximately tested in the sole of the foot by applying alternately the end and the side of a pencil. If they are distinguished, and if the localising and spacing senses are normal, there is no marked loss of the elements furnishing the stereognostic sense in this extremity.)

That such systematic examination will be rewarded is evident from the fact that since the introduction of the study of astereognosis the symptom has been found by Verger in more than half the recent cases of hemiplegia ; by Abba in 8 per cent. of fifty old and recent cases; by Darcum in nearly half of forty-one cases; and by ourselves in 33 per cent. of seventy-three old cases.

It is also desirable that more pains should be taken to investigate in such cases the sensation of the face. No study has been made, as far as we are aware, of "active touch" in the face, and yet the tongue, at least, possesses this function in a high degree. In a case of astereognosis of the right hand, recently seen in consultation with Dr. Phippen of Salem, cloth could not be distinguished from paper on the right side of the tongue though easily distinguished on the left. Contact sense was unaffected. 
This case showed also the importance of testing the ability to handle tools and to write, for the patient, though able to make every movement, and though able to talk fluently, had lost the power of sewing and of writing (except by slowly tracing the letters, by which method she wrote spontaneously and from dictation). This observation tends to show that the stereognostic hand-centre is closely identified with the general kinæsthetic hand-centre, and further, that our search for the writing-centre need not lead us beyond the network subserving these functions. There certainly seems every reason to accept Bastian's suggestion that the cortical structures in which "are registered the sensory impressions produced by writing movements," though functionally related, need not have a separate seat, but may be mingled with those structures concerned in the memories of other hand movements. The existence of a writing-centre in this sense can hardly be doubted, whether its perfect action requires the integrity of Broca's region, or whether it is capable of acting independently of that region in response to appropriate stimuli from the auditory and visual centres. 